\title{
12 \\ Práticas \\ de violência e mortes \\ de torcedores \\ no futebol \\ brasileiro
}




\section{RESUMO}

Este artigo analisa as relações entre a violência e o futebol no Brasil, estudando seus casos extremos: as mortes de torcedores causadas pelos conflitos entre torcidas. O Brasil é um dos países com maior número de mortes entre torcedores de futebol. Dados quantitativos e informações qualitativas foram correlacionados para se entender melhor as causas dessas violências e para se reprimir e prevenir o vandalismo. A metodologia integrou técnicas quantitativas com análises qualitativas, as quais se basearam nos parâmetros dos órgãos da segurança pública e da justiça brasileiras, além de interpretações sociológicas e históricas. A recolha dos dados para o mapeamento dos torcedores mortos foi feita em jornais e revistas, e a confirmação e aprofundamento, nos inquéritos das delegacias policiais.

Palavras-chave: violência, futebol, mortes, repressão, prevenção.

\section{ABSTRACT}

This paper analyzes the relationship between violence and soccer in Brazil, focusing on its extreme cases, such as the death of soccer fans due to conflicts among supporters. Brazil is one of the leading countries in soccer-related violence (deaths included). In order to better understand the violence causes, as well as to repress and prevent vandalism, this research combines qualitative and quantitative data. The research methodology includes quantitative techniques and qualitative analyses, which were based on the parameters used by the Brazilian National Security and the Brazilian Justice System. In addition, the research was also based on sociological and historical facts. The research data used to map the dead supporters were collected from newspapers and magazines; and the confirmation and deeper study from analyzing police investigations.

Keywords: violence, soccer, death, repression, prevention. 


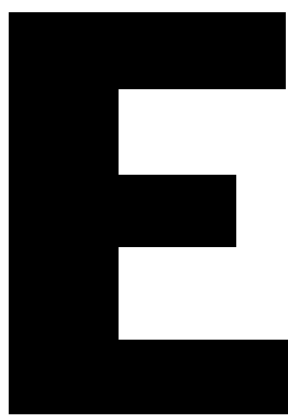

m 2012, o Brasil foi o campeão mundial de mortes de torcedores. Mortes em consequência de conflitos entre torcidas organizadas. Mortes comprovadas. Foram 23 óbitos - ultrapassamos a Argentina e a Itália, e uma década antes estávamos atrás deles. Em 2013, até o final do mês de julho, já eram 15 os homicídos comprovados e 2 ainda não comprovados, mas com fortes indícios, sem contar com o jovem boliviano Kevin Spada, morto em Oruro, Bolívia, atingido por um sinalizador, no jogo San Jose x Corinthians, no dia 20 de fevereiro de 2013.

O que aconteceu e acontece, efetivamente, para termos chegado a essas preocupantes estatísticas? Causas macro e microssociais, estruturais e conjunturais, históricas e culturais, sociológicas e antropológicas devem convergir, de modo articulado, para um entendimento consistente dessa problemática, que agride a nossa consciência coletiva e exige medidas integradas de combate, de curto, médio e longo prazos. E esse quadro provoca, necessariamente, reflexões, investigações, proposições.

O Brasil terá a chance extraordinária de sediar os dois maiores eventos esportivos do planeta, um seguinte ao outro: a Copa do Mundo de Futebol, em 2014, e os Jogos Olímpicos do Rio de Janeiro, em 2016. Situação ocorrida somente em três oportunidades na história do esporte: México, 1968/1970, Alemanha, 1972/1974 e EUA, 1994/1996. Chance rara, tanto no campo esportivo, propriamente dito, quanto no campo social. E neste último trata-se do tão propalado legado, ou seja, a herança sociocultural que esses megaeventos esportivos podem deixar para o país, como um todo, nomeadamente para as suas camadas sociais mais carentes, de recursos e oportunidades, de qualidade de vida, em resumo.

Nosso país está muito atrasado na elaboração de políticas públicas, de caráter sociocultural e educativo, no sentido de aproveitar a Copa do Mundo e os Jogos Olímpicos naquilo que podem deixar incorporados à vida brasileira, à nossa cidadania. Educação, saúde, infraestrutura, saneamento, mobilidade urbana (só pra citar um exemplo: desde a Eco-92 foi prometido um Plano de Transportes Urbanos) e segurança, entre outras, são prioridades, de acordo com as premissas dos respectivos "cadernos de encargo", bem como dos dois contratos assinados com o COI - Comitê Olímpico Internacional e com a Fifa - Federação Internacional de Futebol Associado pelo Estado brasileiro e não apenas pelos governos. Pelo Estado brasileiro, reitere-se. Isso significa que o compromisso firmado em documento público e internacional deveria ser estratégico para o país, com planos e programas combinados de curto, médio e longo prazos, para dar conta, minimamente, do "antes", do "durante" e do "depois" desses grandes acontecimentos.

MAURICIO MURAD é sociólogo, professor adjunto aposentado da UERJ e do mestrado da Universo. 
São dois meageventos subsequentes que, se bem aproveitados (em torno de $67 \%$, isto é, $2 / 3$ daquilo que está previsto nos contratos e nos encargos são considerados o ponto ótimo), poderão trazer resultados expressivos para o Brasil, com desdobramentos possíveis até 2030 ou 2035, segundo estudos de projeção feitos pela FGV em 2008 e atualizados nos anos seguintes. Projeções realizadas na área dos investimentos, na geração de empregos diretos e indiretos, na visibilidade e na respeitabilidade internacionais. E isso tudo não é somente porque as entidades internacionais do esporte exigem não, mas principalmente porque são direitos dos cidadãos brasileiros, direitos previstos na nossa Constituição de 5 de outubro de 1988, firmados na legalidade de nosso sistema jurídico, na legitimidade de nosso sistema político representativo e no que deveria ser a ética do homem público, das autoridades, dos governantes.

No âmbito particular da segurança pública, estamos ainda mais atrasados. Considerada como fator central pelos contratos de Estado e capítulo sublinhado nos Cadernos de Encargo, tanto da Fifa, quanto do COI, "a segurança é pré-requisito, para todos os outros componentes", da organização do evento a seu legado, já que garante "o ir e vir das pessoas" - princípio do direito e da justiça universais - e a paz social, necessária a quaisquer investimentos em quaisquer níveis.

O principal objetivo do trabalho a seguir foi o de mapear as mortes (limite extremo da violência) dentro e fora dos estádios de futebol no Brasil, causadas por conflitos entre grupos de "torcedores organizados". Mais concretamente: mapear, situar o problema, identificar suas causas e contribuir para ajudar no controle e na prevenção da violência desde já, mas também visando, na linha de frente, à Copa do Mundo de 2014, a ser realizada no Brasil, a seguir aos Jogos de 2016 e a seus legados sociais e culturais. Os óbitos foram eleitos como objetos de investigação, e a última década e meia, recortada como espaço temporal, tendo em vista duas dimensões fundamentais, convergentes e complementares: a morte é o grau máximo nas múltiplas e variadas práticas de violência, e o contexto de quinze anos é um recorte temporal suficiente na quantidade e consistente na qualidade para oferecer bases de confiabilidade empírica, bem como fundamentos teóricos e metodológicos, às nossas necessárias e inadiáveis reflexões, investigações, conclusões, proposições.

No Brasil, onde diversas modalidades esportivas são praticadas e são bastante populares, como o al- tetismo, o voleibol, a natação, o basquete, o judô, a capoeira e as chamadas artes marciais, o futebol tem historicamente a preferência de mais de 70\% da população. Essa é a média a que podemos chegar se compararmos as pesquisas, de 2010, de dois institutos conceituados: o Ibope e o Datafolha. E bate também com as pesquisas da Universidade de São Paulo, desde 2001.

O futebol é, portanto, o esporte mais popular e apaixonante, além de mais constante na vida dos brasileiros. Outros esportes que são dignos de nota têm uma oscilação de popularidade por vezes intensa, fenômeno algo sazonal, poderíamos dizer, um ir e vir mais ou menos constante, uma certa variabilidade, em que uns permanecem em destaque por mais tempo, outros nem tanto e alguns ainda têm a sua sustentabilidade popular girando mais em torno de determinado atleta do que da própria modalidade, atleta que se constitui como referência, liderança ou ídolo, casos de Guga, no tênis, Daiane dos Santos, na ginástica, ou Popó, no boxe.

Em princípio, o estudo que gerou este artigo é de cariz descritivo, mas alcança uma esfera analítica, interpretativa, na medida em que se constrói contextualizado histórica e socialmente, na realidade brasileira, em nossos modos de ser, em nossos fundamentos, em nossas contradições. O estudo do futebol é uma via de alcance e acesso às nossas raízes, enquanto coletividade, enquanto historicidade. O presente trabalho tem ainda uma "natureza especulativa" sobre as estatísticas atuais, ou seja, uma intenção projetiva, visando contribuir para intervir e intervir para reduzir esses números de mortes de torcedores de futebol no Brasil. E, no médio e mais ainda no longo prazo, contribuir para melhorar o preocupante panorama da violência em geral de nosso país. Para tanto faz-se necessário um projeto estratégico nacional, com planos e programas que envolvam as múltiplas instituições direta ou indiretamente ligadas ao "espetáculo do futebol", a saber: governos nos três níveis, federal, estadual e municipal, confederação, federações, clubes, treinadores, jogadores, torcedores, mídia, pesquisadores, legisladores, polícias e órgãos da justiça.

O futebol, é óbvio, não é panaceia, remédio para todos os males de nosso país, não, claro que não. Se nem a política, a educação ou a justiça conseguiram reduzir nossa dívida social profunda, não será o futebol a fazê-lo. Entretanto, devido a sua dimensão e impacto simbólicos, o futebol como "esporte das multidões" pode ajudar (ajudar!) a reduzir as práticas 
de violência que se generalizam em todo o território brasileiro. Há uma interação dialética, recíproca e em todas as direções, entre a parte e o todo.

As chamadas macroviolências, que perpassam quase toda a realidade brasileira, como tráfico de drogas, de armas, pedofilia, assassinatos, prostituição infantil, homofobia, trânsito, alcoolismo, brutalidades social, racial e de gênero, entre outras, auxiliam na contextualização das práticas de violência e mortes de torcedores no futebol brasileiro. Em verdade, essas são violências mais no futebol que $d o$ futebol. Manifestam-se no ambiente do futebol, mas não são exclusivas dele.

A contextualização é um método por excelência da análise sociológica e, de uma maneira geral, de toda análise científica daquelas investigações e interpretações em grau sustentável de cientificidade. Poder-se-ia ampliar e dizer ainda que a contextualização (teórica, histórica e social) é um dos aspectos distintivos da análise científica e não somente da sociologia. E isso para tentar uma compreensão mais ampla dos temas investigados, para emprestar maior fidedignidade teórica às reflexões e maior fiabilidade empírica aos resultados e conclusões finais (Murad, 2009, p. 37).

Se é fato que o conhecimento do todo informa dialeticamente a compreensão da parte, também o é que esta, a parte, auxilia no entendimento daquele. $\mathrm{O}$ conhecimento do Brasil passa pelo futebol, teria dito o escritor e jornalista José Lins do Rego (1901-57), um dos intelectuais mais influentes da vida brasileira, que completou afirmando que através do futebol podemos fazer uma psicossociologia da nossa vida sociocultural, de nossas contradições sociais, de nossos dilemas culturais. Fazer isso é fazer sociologia dos esportes e mais detalhadamente sociologia do futebol.

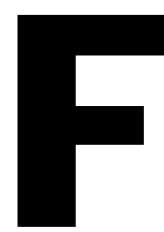

UTEBOL, IDENTIDADE COLETIVA NO BRASIL Nossa formação cultural é um mosaico de várias manifestações relevantes construídas historicamente e muitas delas politicamente, é possível ser dito, como espaços de resistência ao elitismo e à exclusão dominantes em nossa sociedade. São manifestações de intensa expressividade ritual, na música, na dança, religiosidade, culinária, literatura, festas populares, capoeira, futebol, que ajudam sobremaneira a fixar as nossas identidades coletivas. Fixar e consolidar: diga-se. Todas essas manifestações culturais (e outras) são símbolos importantes de nossas coletividades, emblemas populares, que fazem parte de nossas culturas e de nossas mitologias, ou seja, de nossas histórias, lendas, fábulas, signos.

São identidades, além de identificações.

E o que é identidade cultural de um povo, de uma comunidade ou de um grupo? À partida, devemos falar como estamos falando, assim mesmo, no plural: identidades. Sim, porque elas sempre são diversas e variam de acordo com as regiões, as classes sociais, as etnias. E logo a seguir devemos saber que existe uma diferença sociológica significativa entre identidade e identificação.

Identidade tem a ver com o "ser", com as manifestações culturais mais permanentes, que ajudam a entender e a definir um lugar e sua gente.

Identificação tem a ver com o "estar", com as manifestações culturais mais imediatas, mais passageiras e que às vezes tentam até esconder as identidades.

No Brasil (e em outros países), o futebol é uma identidade coletiva, verdadeira paixão e referência, que mexe com quase todas as pessoas, de diferentes grupos e classes sociais, diversos padrões de renda e escolaridade, culturas e regiões. É um símbolo muito forte de nossos valores culturais e representa a nossa sociedade, o nosso modo de ser. Por isso, o futebol, além de um esporte, é um caminho para se entender o próprio país, no que ele tem de "bom" e no que ele tem de "ruim".

E por isso, por esses fundamentos de compreensão teórica, a nossa metodologia de pesquisa procurou articular diferentes níveis e instrumentos de investigação e análise a fim de operar reflexões e propostas no curto, no médio e no longo prazos. Reflexões para se entender de forma mais aprofundada a violência no Brasil e suas manifestações no futebol brasileiro, notadamente em relação à morte de torcedores, e igualmente indicar propostas concretas de intervenção aos organismos de segurança pública do país, para hoje e para o futuro.

Após exaustivos estudos sobre a história das torcidas organizadas no Brasil, revisão da literatura pertinente, fundamentação epistemológica, teórica, metodológica e técnica, o primeiro passo no campo da investigação empírica foi o levantamento de dados e informações sobre as mortes de torcedores desde o início de 1999 até hoje, 2013. À partida, na mídia, basicamente em jornais e revistas. As notícias e narrativas mediáticas fazem parte do conjunto das produções 
sociais e simbólicas e podem servir como "material empírico" para o exercício da análise, como um dos seus pontos de partida, mas não como $o$ ponto de chegada. Torna-se imprescindível interpretar os contextos de interesse nos quais os mass media estão inseridos e considerar o seu grau de poder, imediatismo e superficialidade, na medida em que as fontes não são observadores neutros da vida social.

Desse modo, o noticiário deve representar um dos aspectos da interpretação de cunho científico, não o único e nem o principal. É preciso comparar, contrapor, conferir, dialogar, checar, arguir, questionar, confirmar. No caso de nossa pesquisa ao redor das mortes de torcedores foi imprescindível e inadiável a sua confirmação documental através dos inquéritos abertos nas delegacias policiais da jurisdição para o aprofundamento da chamada "materialidade do delito", qual seja, informações, circunstâncias e perfis dos envolvidos no ato delituoso. $\mathrm{E}$ isso para que se pudesse comprovar, com segurança, que os óbitos eram causados mesmo pelos enfrentamentos bélicos entre torcedores.

Em seguida foi elaborado um quadro de indicadores a fim de mapear especificamente o perfil social, econômico e cultural dos torcedores mortos, bem como sua vinculação ou não com as torcidas organizadas, para servir como ferramenta de acompanhamento dos períodos subsequentes do processo. Além disso, também, enquadrar os delitos comprovados naquilo que a legislação penal vigente no país tipifica como crime, sua tipologia e sanções cabíveis. Delitos correspondem a penas, conforme o postulado clássico de Cesare Beccaria (1738-94), em seu livro Dos Delitos e das Penas, de 1764, referencial à sociologia jurídica e igualmente clássico.

A Constituição Brasileira estabelece em seu artigo 144 que a segurança pública é dever do Estado, direito dos cidadãos e responsabilidade de todos. (Então, por que a resistência em implantar o disque-denúncia das torcidas - garantia do anonimato e parceria com os pacíficos, a maioria - que defendemos faz muito tempo?) À Polícia Militar cabe o combate imediato, a ação ostensiva e/ou preventiva da política de segurança pública, ao passo que a Polícia Civil acolhe os detidos e instaura o processo a fim de apurar a autoria e a materialidade (as circunstâncias) do delito. É o âmbito da chamada polícia judiciária. A partir de então, o processo policial é encaminhado ao poder judiciário para o devido processo legal. Isso é doutrinário.

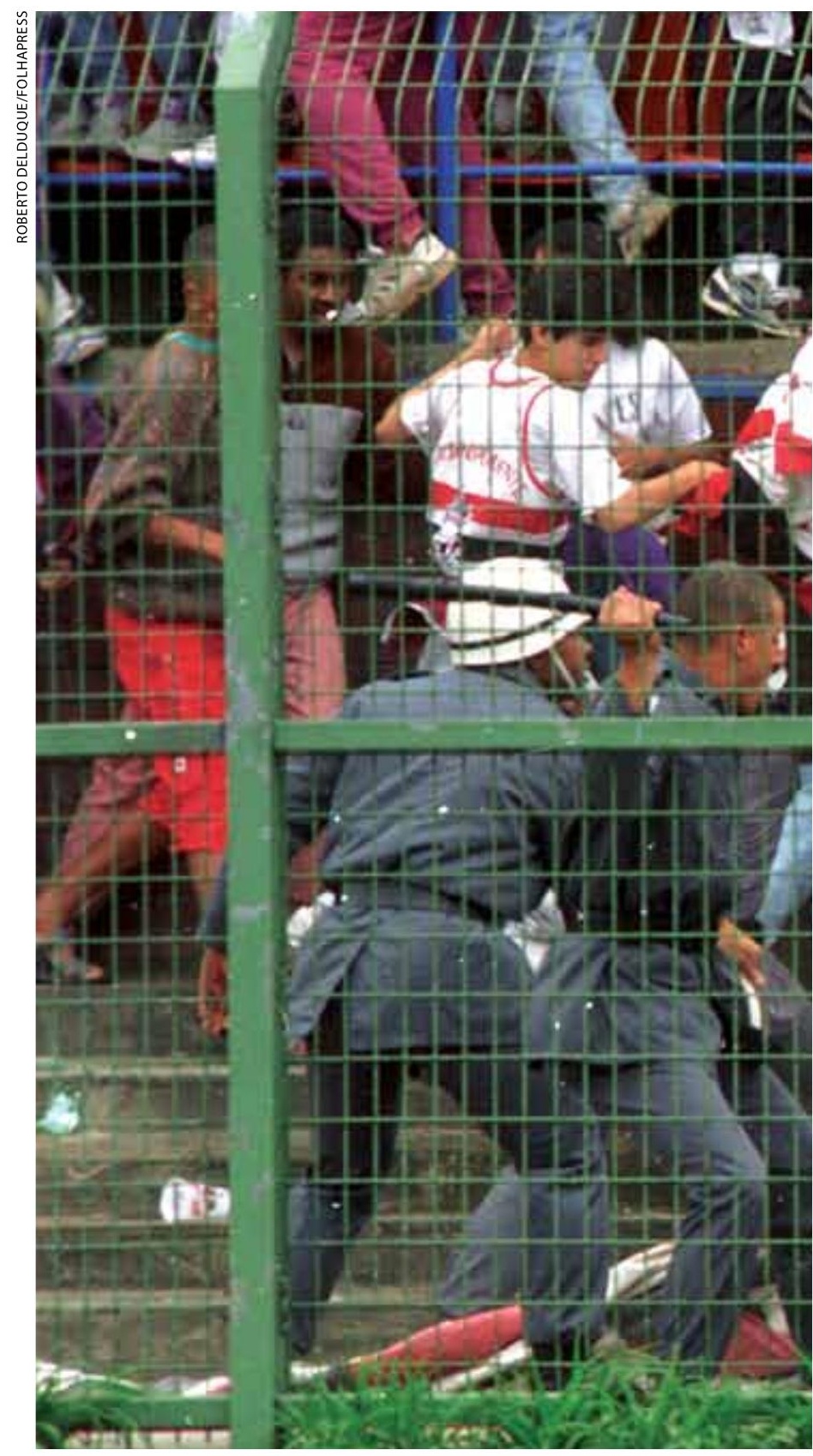

Final da Supercopa São Paulo de Futebol Júnior, no estádio do Pacaembu (1995): cena do conflito no jogo entre Palmeiras e São Paulo em que morreu um torcedor 


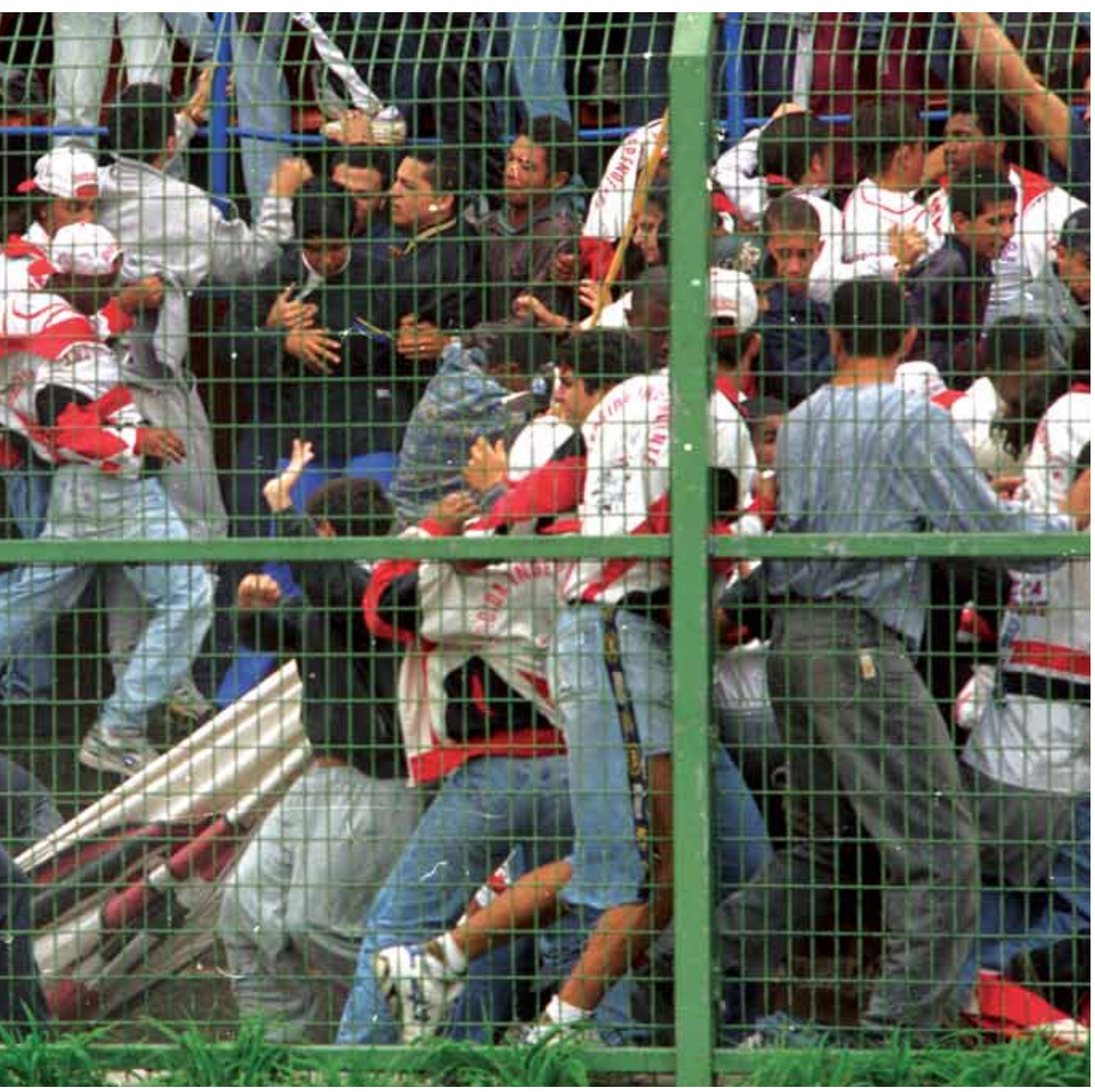

E, assim, o inquérito policial, ao definir a materialidade do crime (o ambiente e as circunstâncias do fato), torna-se um documento (documento primário, no sentido historiográfico) comprobatório da ocorrência do homicídio, se o assassinato aconteceu ou não em consequência de conflitos entre torcidas, ou melhor, entre grupos de torcidas organizadas de futebol. E se é certo que há um conjunto de causas integradas, que ajudam a entender as violências no futebol brasileiro, é certo, do mesmo modo, que haverá complementarmente um conjunto de responsabilidades a serem apuradas e indicadas. A questão mais importante na aplicação de uma penalidadede, isto é, a questão de fundo da "pena", é estabelecer a diferença entre quem fez e quem não fez, entre quem transgrediu e quem não transgrediu. É, pois, uma questão de natureza ética, para além de jurídica. Minimizar esse cenário dantesco de agressões e mortes e reeducar minimamente o torcedor, reduzindo o espaço da barbárie e ampliando o da civilização, são tarefas inadiáveis: a sociedade exige, o futebol merece e a nossa história cobrará.

O futebol é o esporte mais popular do mundo. 
Envolve direta ou indiretamente bilhões de pessoas, entre praticantes amadores, atletas profissionais, torcedores e incalculáveis recursos financeiros e humanos em muitas atividades profissionais e atividades de serviços ao seu redor. É interessante observar e acompanhar que o futebol, além de ser a modalidade mais massiva da história da humanidade, em números absolutos e em números relativos, guardando-se a proporcionalidade entre adeptos e população mundial, é, do mesmo modo, a modalidade esportiva que mais cresce no âmbito internacional. Países como EUA, Japão e China, que não o têm como atividade sociodesportiva de ponta, querem tê-lo, como um meio para integrar-se no chamado "mercado da bola", esse imenso e valorizado mercado global.

É considerado pelos especialistas como o esporte mais espontâneo (pode ser jogado em qualquer espaço) e imprevisível (porque é jogado com os pés), mais simples e barato (não exige maiores equipamentos esportivos), estável (suas 17 regras são universais, existem há muito tempo e quase nunca mudam) e democrático (qualquer um, com qualquer tipo físico, cor de pele, classe social ou cultura pode jogar e jogar bem). Esses fatores ajudam a entender a sua enorme e variada popularidade mundial.

O escritor peruano Mario Vargas Llosa, Prêmio Nobel de Literatura/2010, disse que "o futebol é o ideal de uma sociedade perfeita: poucas regras, claras, simples, que garantem a liberdade e a igualdade dentro do campo, com a garantia do espaço para a competência individual" (Llosa apud Murad, 2002, p. 44). $\mathrm{O}$ futebol é um fenômeno de largo alcance da vida e das culturas coletivas porque ajuda na leitura de nossas contradições, de nossos dilemas sociais e de nossas possibilidades de superá-los. Podemos dizer que dá conta da noção de "veneno-remédio", de Jacques Derrida, inspirada em Platão. Eloquente representação de nossas mazelas culturais e inquietações históricas, uma espécie de pharmakon, em que "veneno" e "remédio" se instalam na mesma presença semiológica, uma semiologia política formada por tensões e até por confrontos*.

\footnotetext{
* "A Farmácia de Platão", 1991, edição em português da lluminuras, é considerado um dos textos mais importantes de Jacques Derrida, cuja publicação original data de 1972, como parte do livro La Dissémination. No que diz respeito à aplicação da ideia de "veneno-remédio", para uma leitura do futebol brasileiro, ver Murad (1996, 2004a, 2004b, 2007a, 2007b) e Wisnik (2008).
}

A Fifa, fundada em 1904, com 208 países associados, em 2013, é a maior entidade de toda a história, maior do que a ONU (1945) e o COI (1894). Sua força política internacional é conhecida e reconhecida. E, pra culminar, a Copa do Mundo é o maior evento da televisão mundial, chegando a algumas dezenas de bilhões de espectadores. Nenhum outro fenômeno, de qualquer tipo, chegou perto desses números. Então, poder-se-ia dizer que o futebol, mais do que uma modalidade esportiva, é uma das maiores manifestações culturais (e democráticas) já vistas.

No caso brasileiro, então, nem se fala. A história do nosso futebol pode ser considerada como parte da história de nossas lutas sociais, de nossos embates contra o elitismo e a exclusão estruturais e históricas em nossa formação social. No Brasil (em outras realidades também), o futebol é bem mais do que um esporte: é uma identidade, um símbolo cultural coletivo e por isso tem tanta importância e exerce tanto impacto na vida de quase todas as pessoas.

De acordo com a CBF (Confederação Brasileira de Futebol), a média de público no Campeonato Brasileiro de 2010 foi de 15 mil espectadores e a de 2011 foi de quase 16 mil, mantendo-se estável, portanto. A título de comparação e para mostrar que essa média foi mesmo baixa, nos EUA ela foi de 17 mil, em 2010, e de pouco mais de 17 mil, em 2011. E estamos nos referindo ao soccer e não ao futebol americano em um país que ainda luta para ter o futebol como um evento de massas destacado. Em 2013, até meados de junho, antes da Copa das Confederações, portanto, nossa média de público era inferior à da Austrália, à da segunda divisão do futebol alemão e continuávamos perdendo para a média dos estádios de futebol nos EUA.

Pesquisa da Universidade do Estado do Rio de Janeiro, Uerj/2009, confirmada por investigação do programa de mestrado da Universo/2011 e 2012, mostrou que, para mais de 2/3 (68\%) dos torcedores, a violência é a maior causa de afastamento do público dos estádios brasileiros, seguida dos preços dos ingressos e da alimentação, do transporte e da falta de conforto nos estádios. Então, há outros motivos, mas destaca-se a violência, particularmente nas saídas dos jogos. Levantamento do IBGE (PNAD - Pesquisa Nacional por Amostra de Domicílios, 2010) confirma que futebol e cinema, nessa ordem, são "as preferências nacionais em matéria de diversão fora de casa", nos nossos centros urbanos e suburbanos, grandes e médios, onde estão concentrados quase $80 \%$ de nossa gente. 
Portanto, é uma contradição o futebol ter essa grandeza para a cultura, o comportamento, a vida das pessoas no Brasil, e a violência afastar essas mesmas pessoas dos estádios, atrapalhar um de seus principais divertimentos. Nossa taxa de ocupação de lugares nos estádios, no último ano, conforme os dados oficiais da CBF, não chega a $22 \%$ do total disponível, o que soma um encalhe de quase 55 milhões de ingressos. Indiscutíveis prejuízos econômico-financeiros e simbólicos. Estamos diante da manifestação concreta da categoria teórica que os economistas chamam de "utilidade marginal decrescente", ou seja, a novidade atrai o consumo imediato, mas não fideliza o consumidor no médio e no longo prazos.

E mais: isso fere importantes direitos constitucionais da nossa cidadania, como o direito de ir e vir, o direito à segurança, ao lazer, ao esporte. A atual Constituição Brasileira, de 5 de outubro de 1988, consagra em seu artigo 217 que o esporte, como prática e como lazer, é um direito dos cidadãos e um dever do Estado. E, mais adiante, o artigo 227 amplia para as instituições básicas de nossa sociedade, como a família e a escola, essa obrigação constitucional do Estado brasileiro. O desporto, portanto, é um dos direitos essenciais de nossa cidadania e assim está consagrado sob o manto da legislação vigente no país e de sua própria Carta Magna.

Subsidiariamente à nossa lei maior (1988), há uma série de instrumentos jurídicos, legais, normativos e éticos, como o Código Brasileiro de Justiça Desportiva (2009), o Estatuto de Defesa do Torcedor (2003-10), o Código de Defesa do Consumidor (1990), a Lei do Crime Organizado (1995). Então, não é falta de legislação, mas de punição, punição efetiva e levada até as últimas consequências. João Capistrano de Abreu (1853-1927), escritor e historiador clássico de nossa história colonial, teria dito ironicamente que, se tivesse que escrever uma constituição brasileira, esta teria apenas um capítulo: cumpram-se as leis já existentes e revoguem-se as disposições em contrário. "Impunidade e corrupção, os males do Brasil são" (Murad, 2012, p. 39).

As práticas de violências em nosso futebol e as mortes de torcedores são operadas por minorias, entre $5 \%$ e $7 \%$, das torcidas organizadas, de acordo com as nossas pesquisas (Uerj/Universo, 2013), levadas a efeito desde maio de 1990. Minorias, mas perigosas e preocupantes, porque armadas, treinadas e organizadas para o confronto violento. Minorias que se criam e crescem, contaminando grupos de "torcedores periféricos" - isto é, aqueles que ficam à sua volta nos estádios, nas entradas e nas saídas dos mesmos -, contaminando e assim podendo ampliar os agentes do vandalismo na ausência da aplicação severa da lei, do uso preventivo, inteligente, das câmeras de monitoramento nas arenas, da intercepção telefônica (incluindo nextel) e eletrônica, de policiamento ostensivo e preparado para lidar com multidão, na falta de melhores condições de vida e de oportunidades, no descaso dos governantes e de autoridades públicas, "que quase nunca são públicas e nem sempre autoridades", parafraseando Karl Marx (1818-83), este relativamente à "opinião pública”. E esse quadro não é privativo do futebol, mas equivalente a outros setores de nossa vida social, em que as violências se manifestam em escala crescente, como no trânsito, na escola, no desaparecimento de menores, na pedofilia, na prostituição infantil, no alcoolismo e nas drogas - vide as cracolândias.

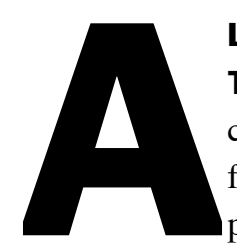

LGUNS ELEMENTOS DE CONTEXTUALIZAÇÃO Historicamente, somos considerados os melhores do mundo em futebol, o maior celeiro e o maior exportador de craques e talentos. O único país que participou de todas as copas, anfitrião de dois mundiais (1950 e 2014) e o único pentacampeão. Tudo isso dentro das "quatro linhas", dentro do campo. Fora dos gramados é outra conversa. Nesse segmento, ainda somos considerados frágeis em nossos modelos de gestão e negócios, estrutura dos clubes, de federações e em segurança pública. Em segurança pública, reitero.

Alguns exemplos eloquentes de contextualização.

Do final de 2009 ao final de 2010, o governo do estado Rio de Janeiro diminuiu (diminuiu!) seus gastos com segurança pública de $12,1 \%$ para $8,6 \%$ do orçamento estadual. Quase 30\%, proporcionalmente. E no Rio de Janeiro, primeira cidade a ganhar o título de Patrimônio Cultural da Humanidade, em junho de 2012, sede dos Jogos Olímpicos de 2016 e uma das sedes da Copa do Mundo de Futebol, em 2014, bem como de seu "ensaio-geral", a Copa das Confederações, em 2013. Outros acontecimentos de massa mostraram igualmente a nossa fragilidade em termos de segurança pública, mais ainda quando se trata de multidões. A jornada mundial da juventude, JMJ, com o papa Francisco, em julho de 2013, no Rio de janeiro é o exemplo mais recente e insofismável. 
De acordo com o levantamento realizado pela Fundação Getúlio Vargas, Boletim de 2011, o país movimentará 142,39 bilhões de reais adicionais no período 2010-14, gerando 3,63 milhões de empregos por ano e mais de 63 bilhões de reais de renda para a população. Do total de gastos estimados para a Copa, projetados inicialmente, mas já corrigidos, de $\mathrm{R} \$ 29,6$ bilhões de reais, $\mathrm{R} \$ 12,5$ bilhões terão como origem o setor público (42\%) e R \$ 17,16 bilhões serão provenientes do setor privado (58\%). A correção de percurso feita para a Copa das Confederações, e denunciada pelas manifestações populares de junho de 2013, foi alarmante: somente $4 \%$ vieram integralmente da iniciativa privada.

E mais grave é que nenhum plano estratégico nacional de segurança pública para o futebol foi tornado público. (Também não há planos convincentes para transporte, saneamento, equipamentos esportivos.) Nem de curto prazo, menos de médio e nada de longo prazo, como mandam os padrões e protocolos internacionais de segurança coletiva a megaeventos esportivos. No máximo, o que apareceu foram medidas isoladas de treinamento de repressão a eventuais sequestros e "atos de terrorismo", sem maior aprofundamento e alcance, sem embasamento científico e consistência, além da compra de equipamentos de altíssima tecnologia e altíssimos preços.

A Firjan (Federação das Indústrias do Estado do Rio de Janeiro), a segunda mais importante entidade empresarial do Brasil, em seus relatórios do ano de 2012, foi mais longe e chegou a projetar um total de negócios de 212 bilhões de reais para o período até os Jogos Olímpicos do Rio de Janeiro de 2016. Então, os volumes de negócios, investimentos, recursos internos e externos, visibilidade internacional do país e aquecimento da nossa economia são de fato impressionantes, desde que bem aproveitados. Reitere-se: desde que bem aproveitados.

A história do olimpismo e das copas de futebol tem exemplos positivos a demonstrar, destaques para os Jogos Olímpicos de Barcelona, em 1992, e o Mundial de Futebol da Alemanha, em 2006. Complementarmente, pode ser incluído aqui nesta listagem o legado da política desportiva global do Principado de Andorra, localizado nos Pirineus, entre Espanha e França, que numa década (1993-2003) aumentou em 63\% o nível do emprego e em $50 \%$ a renda média nacional.

Todas as enquetes e investigações são unânimes em apontar a segurança como fator decisivo para que todas essas possibilidades de aplicações, investimen- tos, empreendimentos venham a acontecer de fato. Então, o aspecto segurança pública é sempre fundamental para o equilíbrio da vida em sociedade e do próprio sentido daquilo que historicamente chamamos de civilização (Elias, 1995). É “a força do Direito contra o direito da força”, para empregarmos a clássica sentença de Rui Barbosa (1849-1923), advogado e vice-presidente do Senado da República Brasileira de então, no Congresso Internacional de Haia, em 1907. Isso vale para a vida social em seu conjunto, e também é muito importante quando se trata de megaeventos esportivos. Nomeadamente, naquilo que se conceitua como legado, ou seja, o que ficará incorporado como herança na existência da sociedade e das pessoas. Afinal, as perspectivas são muito boas e não temos o direito de desperdiçar essas grandes oportunidades que foram abertas ao país. São compromissos de Estado, como já dissemos, para além de compromissos dos governos.

E para atender a todas essas demandas que estão ou deveriam estar em curso e aumentar a nossa capacidade produtiva, em bens e serviços, o país precisa, entre tantas outras coisas, desenvolver - o que não está acontecendo - mão de obra qualificada em variados setores e uma infraestrutura que atenda às necessidades desses eventos, os quais têm logísticas tão complexas. A falta de planejamento em bases sólidas e fundamentadas em pesquisas com alto grau de confiabilidade acaba por desperdiçar oportunidade e majorar os preços, tendo em vista as conhecidas "pressas de última hora". A nossa legislação prevê a categoria "obras emergenciais", as quais dispensam licitação por causa do caráter de urgência que justifica o empreendimento ou a medida: calamidade pública, saúde coletiva, segurança nacional. Mas somente nesses casos. Instrumento jurídico para situações extremas, tem sido utilizado pelo poder público de forma recorrente, excessiva e muitas vezes por interesses subalternos.

Essa situação já ocorreu em diferentes momentos e atividades no Brasil, e também no âmbito desportivo, por ocasião dos Jogos Panamericanos de 2007, no Rio de Janeiro, cujo descontrole dos gastos públicos e os desmandos relativamente ao que foi prometido como compromisso de governo e não foi cumprido - inclusive, sublinhe-se, no emprego da ferramenta "obras emergenciais" - fizeram com que o TCU, o Tribunal de Contas da União, não aprovasse até hoje as contas públicas do referido evento. O caso das balsas australianas, de altíssima tecnologia e altíssimo 
custo, para fins de despoluição da Baía de Guanabara e da Lagoa Rodrigo de Freitas, é um dos exemplos paradigmáticos.

O futebol como "fato social total" ajuda a compreender as contradições de uma sociedade e, por isso, alcança uma significação ampla e suas simbologias transformam-se em objeto de estudo para as ciências sociais. Marcel Mauss conceitua "fato social total como aqueles fenômenos complexos, pelos quais o conjunto das instituições se exprime e o todo social pode ser observado", no "Ensaio sobre a Dádiva" (1925), coletânea de textos intitulada Sociologia e Antropologia (Mauss, 1974), embora "a noção esteja presente em toda a sua obra” (Lévi-Strauss, 1970, p. 149).

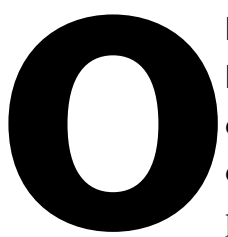

\section{PAN 2007/RJE A SEGURANÇA PÚ-} BLICA Realizados na cidade do Rio de Janeiro, os Jogos Panamericanos de 2007 mobilizaram expectativas, promessas e investimentos, além das comunidades locais, que se manifestaram nas ruas, em apoio a esse evento esportivo da Odepa (Organização Desportiva Panamericana), fundada em 1940, com sede na Cidade do México e atualmente com 42 países-membros.

À época, com a perspectiva da eleição para abrigarmos a Copa de 2014 e os Jogos de 2016 - o que acabou acontecendo -, somado às nossas pesquisas sobre violência no esporte e segurança pública, que vinham desde 1990, inicialmente pelo Departamento de Ciências Sociais da Uerj e depois pelo Programa de Mestrado da Universo, decidimos fazer uma convergência: investigar, analisar e acompanhar o planejamento da segurança pública para o Pan como parte de uma "pesquisa-processo". Poderíamos categorizar "pesquisa-processo" como uma investigação contínua, cuja metodologia vai incorporando complementarmente novas dimensões do "objeto de estudo", com novos recortes temporais e/ou espaciais. Assim, estudar a segurança do Pan 2007 foi um capítulo para o estudo mais geral da segurança pública e o futebol, que segue incluindo os megaeventos de 2014 e 2016.

Durante 21 dias, em julho de 2007, uma equipe de 6 pesquisadores, 1 estatístico e 1 coordenador percorreu as 15 áreas esportivas, polos e complexos nos quais o Rio de Janeiro foi dividido. Foram aplicados 2.410 questionários em pessoas de idades, classes sociais, renda, escolaridade e bairros distintos para que a amostra fosse bem representativa, quantitativa e qualitativamente. O objetivo principal do trabalho foi avaliar o legado da segurança dos Jogos Panamericanos de 2007 no âmbito específico do campeonato carioca de futebol e a seguir no campeonato brasileiro. E isso foi assim definido na fundamentação teórica, metodológica e técnica da pesquisa porque havia um fato social relevante - fazia duas décadas que os conflitos bélicos entre torcedores tinham chegado às páginas policiais, em quantidade e gravidade, dentro e fora dos estádios.

O resultado mais relevante da pesquisa foi que 93\% dos consultados afirmaram ser a segurança uma precondição para a qualidade de vida, a sua garantia. E $68 \%$, isto é, um pouco mais do que $2 / 3$, disseram que não iam mais aos estádios de futebol por várias razões, mas a principal delas era a violência, e concluíram que o Pan "deveria deixar esse legado", o controle do vandalismo nos estádios e em suas áreas adjacentes, embora 83\% não acreditassem que isso fosse ocorrer de fato. "Desejamos, mas não acreditamos", diz um dos depoimentos.

Precariedade dos transportes coletivos, dificuldade de estacionamento, flanelinhas, cambistas, pouco policiamento (em especial, no horário de saída), pouca iluminação das ruas, roubos, assaltos e agressões foram reclamações frequentes. Todos esses indicadores listados pela população já estavam na ordem do dia desde os anos de 1990, apontados por nossos levantamentos e relatórios, e nenhuma medida consistente fora implementada. A esperança era que o Pan pudesse incentivar o poder público e as autoridades federativas na tomada de atitudes a fim de minimizar aquele quadro de confrontos, agressividades e mortes entre torcedores, que completava 20 anos.

Uma expressiva maioria, $72 \%$, achava muito ruim o comportamento das polícias em grandes eventos, celebrações que agrupavam significativo número de pessoas, muita gente ou até multidões. "A polícia está totalmente despreparada, está por fora, só sabe bater!" Reclamaram que a polícia é estranha aos eventos e às pessoas que fazem os eventos. "Isso agora com o Pan é só pra gringo", declararam na incidência de $78 \%$, e "não ficará para depois, para a vida da cidade". O policiamento ostensivo foi considerado o maior "ganho" do Pan 2007 no que diz respeito à segurança pública. Uma das conclusões mais repetidas pelos depoentes é que, apesar disso, embora fosse consenso esse "ganho" nas duas semanas do Pan, o policiamento ostensivo não teria continuidade. "É somente aparência, é pra inglês ver". 
Outro aspecto de suma importância, que apareceu como conclusão da pesquisa, é que as pessoas que responderam o questionário reivindicaram maior "espírito público" dos governantes, nos três níveis de poder, federal, estadual e municipal, no sentido de trabalharem mais e melhor na criação e melhoria das condições de vida, sobretudo para as classes desfavorecidas, e na aplicação rigorosa das leis existentes. Nomeadamente entre os jovens (15 a 24 anos), a conjugação dessas duas medidas foi mais frequente, uma de longo prazo e outra de curto prazo, a saber, "melhores condições de vida" e "aplicação dura da lei". Nesse ponto, a pesquisa revelou mais do que um resultado ou uma conclusão, mas uma sabedoria, sabedoria que é mais ou menos inquestionável e consensual, quase conceitual.

Em relação aos possíveis megaeventos, possíveis naquele ano de 2007 , hoje uma realidade, e bem próxima, a Copa do Mundo de 2014 e os Jogos de 2016, os entrevistados ficaram divididos. Tabuladas as respostas, $45 \%$ declararam que eram contra novos grandes eventos esportivos internacionais no Brasil para que não se repetisse o "vexame" do Pan 2007 e 55\%, ao contrário, afirmaram que a Copa e as Olimpíadas poderiam e deveriam realizar aquilo que o Pan não conseguiu, até porque a Fifa e o Coi são entidades muito mais fortes, organizadas e reconhecidas no mundo do que a Odepa. Estatisticamente, quase um empate técnico, apesar de a esperança em novas possibilidades e a confiança nas maiores e mais poderosas entidades esportivas mundiais acabarem por predominar.

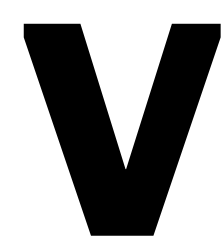

IOLÊNCIAS E MORTES ENTRE TORCEDORES Paralelamente à pesquisa acima relatada sobre o Pan 2007, nossos diagnósticos continuaram. Já eram e permaneceram sendo levantamentos e pesquisas, reflexões e estatísticas acerca das práticas distintas de violências e mortes de torcedores, basicamente por conta de grupos transgressores, delinquentes e delituosos infiltrados nas torcidas organizadas, minoritários, mas radicais e preocupantes. Entrelaçamentos interpretativos, entre números, ideias, análises, teorias, experiências nacionais e internacionais, sentidos e propostas, para entender e minorar mais esse quadro trágico da realidade brasileira.

Na década de 1999 a 2008, que contextualizou o nosso trabalho do Pan 2007, fomos os campeões mundiais nas mortes de torcedores se compararmos nossos levantamentos e sondagens com os efetuados no chamado "primeiro mundo do futebol", em que as pesquisas sobre confrontos de torcidas e mortes de torcedores são mais sistemáticas, consistentes e confiáveis. $\mathrm{Na}$ teoria, na metodologia e na técnica de campo. O período contabilizou 42 mortos, uma média de 4,2 por ano. Ultrapassamos a Itália e a Argentina, que estavam à frente do Brasil no início do decênio investigado.

Tais países se organizaram e agiram com firmeza na repressão, com inteligência na prevenção e com políticas de governo na reeducação do público de futebol, em geral, e, mais especificamente, junto às torcidas organizadas. Lamentavelmente, o mesmo ainda não se deu com o Brasil, e chegamos a esses resultados extremos, repetidos ano a ano e em escala crescente. Mas o pior é a escalonagem dos números de mortes se segmentarmos o assunto por subperíodos: na década avaliada, a média anual foi de 4,2 óbitos, mas, nos últimos cinco anos (2004-08), o número aumentou para 5,6 e, nos dois últimos (2007 e 2008), para 7 homicídios ao ano.

Os diagnósticos continuaram ininterruptamente. Os dados ao redor das mortes comprovadas de torcedores não pararam de crescer, sem que medidas repressivas e preventivas fossem tomadas efetivamente. Em 2009 alcançamos 9 mortos, em 2010, 12, em 2011, 11, e em 2012, 23 assassinatos de torcedores em razão de confrontos e conflitos entre as organizadas. Campeões mundiais na década e também nesse ano de 2012. Mais grave ainda é que a maioria desses mortos não tem ligação direta com grupos de marginais infiltrados nas torcidas. Por efeito, a violência no futebol faz eco à violência macrossocial do Brasil: a maioria das vítimas não faz parte dos grupos agressores e transgressores, os quais são os verdadeiros culpados pelos confrontos, conflitos, lesões graves e mortes. No ano de 2012, a região da Grande Goiânia (Goiás), com 7 mortes, e a região da Grande Fortaleza (Ceará), com 5, destacaram-se no quadro geral dos estados brasileiros.

Como já foi apontado no início deste artigo, até o final de julho de 2013, foram 15 os mortos comprovados e 2 ainda sob inquérito policial, todavia com fortes indícios de comprovação, e isso sem contar a morte do adolescente Kevin Spada, na Bolívia, fora do país portanto, mas envolvendo torcedores brasileiros. Esse número contabilizado já projeta um total de óbitos em 2013 superior a 2012, e isso sem considerar que o campeonato brasileiro ainda não chegou a suas rodadas decisivas, nas quais historicamente os 


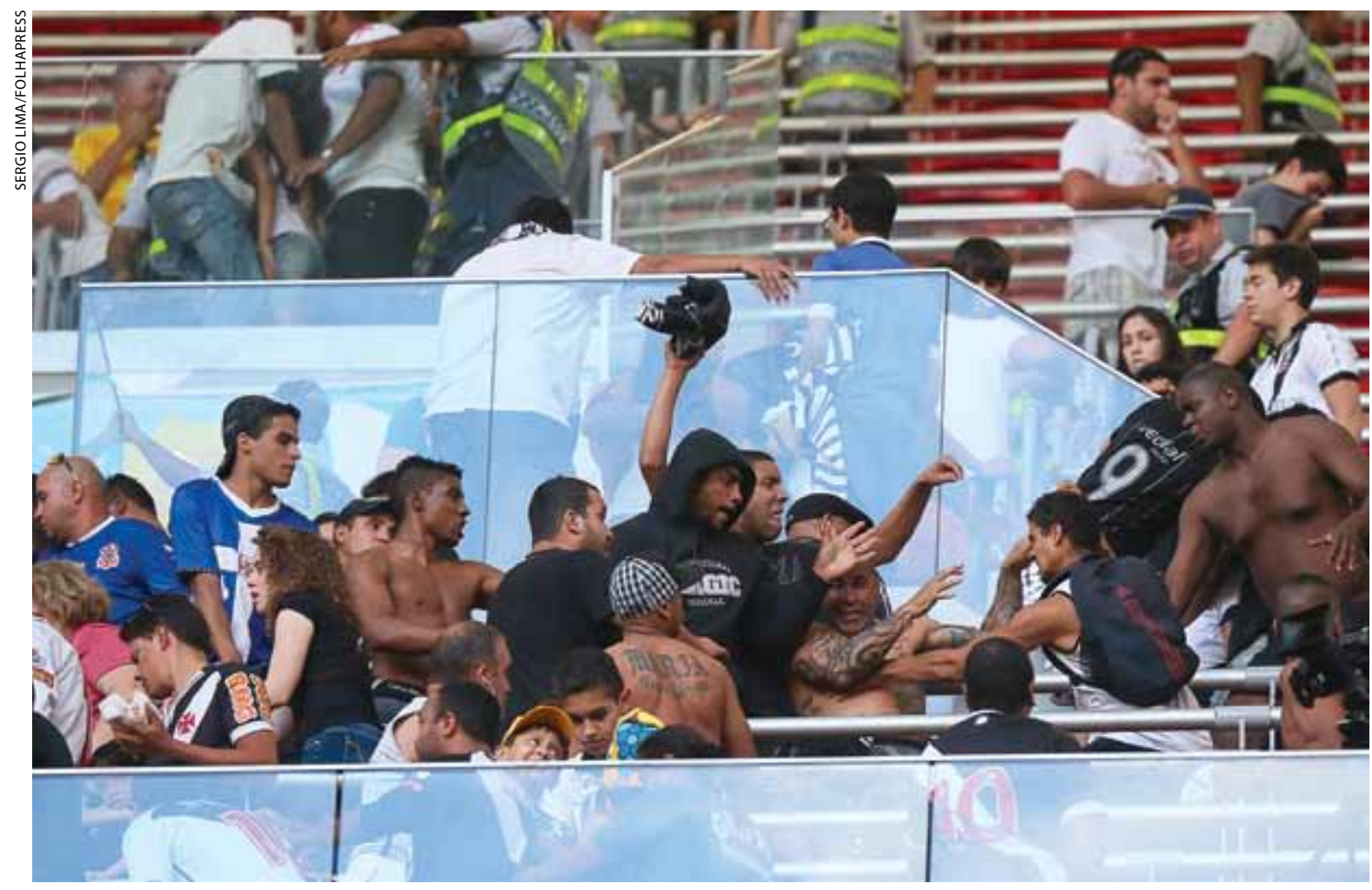

Torcedores do Corinthians e do Vasco brigam durante intervalo da partida, no Estádio Mané Garrincha, em Brasília

ali bem mais do que em outras regiões do Brasil, embora o quadro global do país seja gravíssimo. Assim, o todo da região contextualiza e ajuda a entender a parcela que cabe ao futebol. O Brasil é um dos países mais violentos do mundo, no trânsito, em homicídios, no desaparecimento de jovens e também no futebol. E sem falarmos nas violências estruturais e históricas, confrontos são mais acirrados e se aprofundam em quantidade e gravidade.

A região da Grande Natal (Rio Grande do Norte) geminada com o município de Mossoró $(285 \mathrm{~km}$ da capital do estado, importante polo econômico - sal e petróleo - e cultural) totaliza 5 mortes. A cidade de Campina Grande (Paraíba), a 110 km de João Pessoa, polo econômico, universitário e turístico de proa no estado, com 2 óbitos, também merece uma atenção específica por parte das autoridades da justiça e da polícia. Nesse período fechado até agora, de sete meses, do exercício de 2013, estados do Nordeste destacaram-se no quadro estatístico brasileiro e estão exigindo atenção especial, reitere-se.

Mas por que, até agora, encontram-se à frente das estatísticas de 2013? O Mapa Nacional da Violência, do mesmo ano, ajuda a entender os porquês: o tráfico de drogas em geral e a cracolândia, em particular, os homicídios violentos e as rixas e vinganças entre famílias e grupos nordestinos (herança do histórico coronelismo regional) cresceram proporcionalmente o colonialismo, a escravidão (fomos o último país do mundo a abolir esse sistema de trabalho), exclusões e preconceitos. As pesquisas daqui e de fora comprovam isso. $\mathrm{O}$ futebol é mais do que uma modalidade esportiva, é a expressão profunda das contradições e dos dilemas de nossas realidades.

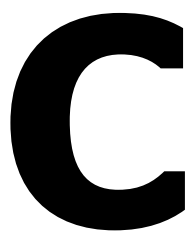

ONCLUSÕES Considerando que esta investigação, como é óbvio, está inserida nas reflexões mais amplas da violência, da chamada violência geral, julgamos oportuno pensar também a própria palavra violência. Violência vem do latim violentia (vis = à força) e significa oprimir por meio da força - força social, das armas, força física, força simbólica. "Por violência entende-se a intervenção física de um indivíduo ou grupo contra outro indivíduo ou grupo (ou até contra si mesmo). [...] a violência consiste, tem por finalidade, destruir, ofender e coagir. [...] A violência pode ser direta ou indireta" (Bobbio, 1995, p. 1.291). 
Isso no que respeita ao conceito geral de violência, das práticas de violência observáveis na história.

Não se pode negar a violência no futebol, no futebol brasileiro, dentro e fora de campo. E, em particular índice de gravidade, a mais extremada das violências, qual seja, a morte de torcedores. Suas fontes de consulta são a mídia, as delegacias policiais, os institutos médico-legais, as federações e a pesquisa acadêmica. Contudo, nosso referencial de investigação é que a violência no futebol é periférica e não estrutural, grave, mas inferior à sua dimensão não violenta e sociopedagógica; são práticas de violência no futebol e não do futebol. Nosso princípio é o de que esse desporto não é "violento em si”, ao contrário daquilo que muitas vezes transparece na espetacularização da mídia (Debord, 1971) e no imaginário popular.

O futebol é um grande evento da "cultura das multidões", com manifestações de ambiguidade, embora as tendências "positivas" sejam superiores às "negativas". Entretanto, as distintas práticas de violência no mundo do futebol, seu lado mais obscuro e preocupante, muitas vezes se sobrepõem ao espetáculo, no melhor sentido da palavra, como cultura popular, criatividade coletiva, identidade, sociabilidade, sentimento de pertença. É em defesa dessa modalidade esportiva, por tudo o que ela é e pelo que pode ser, que se coloca nossa investigação sobre as práticas de violências e mortes de torcedores no futebol brasileiro. E do mesmo modo colocamos a proposta de um projeto estratégico nacional de segurança pública para o futebol brasileiro, com indiscutíveis efeitos para a segurança global de nosso país. Projeto contínuo e aprofundado, compromisso coletivo de um conjunto de instituições federais, estaduais e municipais, adequado às culturas dos diferentes lugares e constituído por planos e programas integrados de curto, médio e longo prazos, respectivamente de repressão, de prevenção e de reeducação.

\section{BIBLIOGRAFIA}

BOBBIO, Norberto. Dicionário de Política. Brasília, UnB, 1995.

DEBORD, Guy. Société du Spectacle. Paris, Champ Libre, 1971.

ELIAS, Norbert. Em Busca da Excitação. Lisboa, Difel, 1995.

HOLANDA, Bernardo Borges Buarque de. O Clube como Vontade e Representação: o Jornalismo

Esportivo e a Formação das Torcidas Organizadas de Futebol no Rio de Janeiro. Rio de Janeiro, 7 Letras/Faperj, 2010.

LÉVI-STRAUSS, Claude. "Introdução à Obra de Marcel Mauss", in Estruturalismo: Antologia de Textos

Teóricos. Rio de Janeiro, Martins Fontes, 1970.

MAUSS, Marcel. "Ensaio sobre a Dádiva”, in Sociologia e Antropologia. São Paulo, Edusp, 1974.

MURAD, Mauricio. A Violência e o Futebol - dos Estudos Clássicos aos Dias de Hoje. Rio de Janeiro, FGV, 2007.

. Sociologia e Educação Física - Diálogos, Linguagens do Corpo, Esportes. Rio de Janeiro, FGV, 2009.

. Para Entender a Violência no Futebol. Coleção Benvirá. São Paulo, Saraiva, 2012.

TOLEDO, Luiz Henrique de. Torcidas Organizadas de Futebol. São Paulo, Anpocs/Autores

Associados, 1996.

WISNIK, José Miguel Soares. Veneno Remédio - o Futebol e o Brasil. São Paulo, Companhia das Letras, 2008. 